\title{
Influence of various acids on the physico-mechanical properties of pozzolanic cement mortars
}

\author{
S TÜRKEL, B FELEKOǦLU and S DULLUÇ \\ Department of Civil Engineering, Dokuz Eylül University, 35160, Izmir, Turkey \\ e-mail: selcuk.turkel@deu.edu.tr
}

MS received 18 November 2005; revised 28 September 2007

\begin{abstract}
Acidic attack represents a topic of increasing significance, owing to the spread of damages of concrete structures in both urban and industrial areas. Cement type is an important factor affecting performance of cement based materials in an aggressive environment. The goal of this study was to compare the acid resistance of a pozzolanic cement (CEM IV-A/32.5) with Portland cement (CEM I 32.5) that was made from the same clinker. For this purpose, $50 \mathrm{~mm}$ mortar cubes were prepared with two different kinds of cement according to TS EN 196-1. After 28 days of hardening, the samples were immersed into four different concentrations of hydrochloric, nitric and sulfuric acid solutions for a period of 120 days. The changes in weight loss and compressive strength values for each acid solution within the test period were recorded. The acid resistance of mortars made from Portland cement was better than the pozzolanic cement incorporated samples after 120 days of acid attack.
\end{abstract}

Keywords. Pozzolanic cement; hydrochloric acid; nitric acid; sulfuric acid; loss of weight; compressive strength.

\section{Introduction}

Durability is an important engineering property of concrete, which determines the service life of concrete structures significantly. Due to the interactions of concrete with external influences, the mechanical and physical properties of concrete may be threatened and lost. Among the threatening factors like freezing and thawing, abrasion, corrosion of steel, chemical attack may also deteriorate concrete within time.

ACI Committee Report 201 (2001) has classified chemical attacks into several types that include; acidic attack, alkali attack, carbonation, chloride attack, leaching and sulfate attack. It can be accepted as a general rule that acids are deleterious to concrete.

The spectrum of aggressive acidic media is wide. Acidic attack usually originates from industrial processes, but it can even be due to urban activity. Even natural exposure conditions may cause acid attacks. Free acids in natural waters are rare. Exceptions are carbonic waters and sulfurous and sulfuric acids in peat waters. Soils may contain huminous acids. Several organic and inorganic acids may occur in shallow regions of sea-water as a consequence 
of bacteriological activity. Significant quantities of free acids in plants and factories may be found. In these cases, the concentration of acid, which comes in contact with concrete structures, may reach to high values (Ecob \& King 1990; Baradan et al 2002).

The degree of aggressivity of an acid is dependent on the chemical character of anions present. The strength of acid, its dissociation degree in solutions and, mainly, the solubility of the calcium salts formed are dependent on the chemical character of anion. The acidic attack is affected by the processes of decomposition and leaching of the constituent of cement matrix (Gutt \& Harrison 1997; Mehta 1986). An acidic media may achieve values under 7 , predominantly 6 and lower. However, $\mathrm{pH}$ values give no correct information about the real quantity of the acid in the solution, because the $\mathrm{pH}$ value is dependent on the dissociation degree of acid. Besides, for the aggressivity of acidic solutions, the real concentration of acid is more significant than pH value (Živica \& Bajza 2001; Živica \& Bajza 2002).

Aggregate type also affects the performance of mortars against acid attack. Limestone aggregate is more vulnerable to acid attacks. However, aggregates like river gravel and similar silicious materials are more resistant (Živica \& Bajza 2001; Rostam 1997; Neville 1997).

The type of cement is another factor affecting the performance of concrete in an aggressive environment. It is known that acids are always hazardous on any type of cement (Parrot 1991; Alegre 1978). The integrity of hardened Portland cement binders is highly dependent on maintaining the high levels of alkalinity which normally stabilize the gel compound responsible for cementitious properties. Acids react with alkaline components of the binder (calcium hydroxide, calcium silicate hydrates and calcium aluminate hydrates) lowering the degree of alkalinity. In extreme cases, acids may completely neutralize the alkalinity. These chemical changes are disastrous and disintegration of the matrix is the inevitable result. Portland cements are the most vulnerable cement type to acidic attack, since they contain a high proportion of calcium hydroxide released during hydration of the calcium silicates (Hewlet 1997). According to Zivica and Bajza (2002) blended Portland cements with pozzolans and slags are considered to be more resistant to the acidic attack than Portland cements. It should also be considered that, the efficiency of blending for acid resistance may be affected by other factors e.g. the type of cement used for blending, the amount and fineness of pozzolan used and especially curing conditions (Hewlet 1997; Mehta 1985; Calleja 1980). Nevertheless, the blended Portland cements with pozzolans, such as blast furnace slags, fly ashes and others, have slow strength gain and hence slow reduction in permeability properties at early ages. Additionally, these cements are more curing sensitive than Portland cement (Živica \& Bajza 2001).

While the cement types differ in their degree of resistance to acids, these differences are small and none of the concretes made with such materials is truly and continuously resistant to inorganic acids. Currently emphasis is towards producing dense and compact highperformance concrete to achieve durability and better performance of concrete in aggressive environments.

There exist a number of factors that control hardened cement pastes deterioration in acid solutions. These include the type, the concentration and $\mathrm{pH}$ of the acidic solution, the mobility of the solution, the water/cement ratio, the type of cement and mineral admixtures (Pavlik \& Uncik 1997).

The signs of acidic attack are loss of alkalinity (also disturbing of electrochemical passive conditions for the embedded steel reinforcement), loss of mass, loss of strength and rigidity. These degradation effects are gradual (Regourd 1981).

Despite the fact that various physical and chemical tests on the resistance of concrete to acids have been developed, there are no standard procedures available (Hewlet 1997). It is essential that tests performed under realistic conditions because, when a concentrated acid 
Table 1. Chemical analysis, physical and mechanical properties of cements.

\begin{tabular}{|c|c|c|}
\hline \multirow{2}{*}{$\begin{array}{l}\text { Chemical composition } \\
(\%)\end{array}$} & \multicolumn{2}{|c|}{ Cement type } \\
\hline & CEM I-32.5 & CEM IV-A/32.5 \\
\hline $\mathrm{SiO}_{2}$ & 19.96 & 29.89 \\
\hline $\mathrm{Al}_{2} \mathrm{O}_{3}$ & $4 \cdot 33$ & $7 \cdot 33$ \\
\hline $\mathrm{Fe}_{2} \mathrm{O}_{3}$ & 4.43 & $4 \cdot 20$ \\
\hline $\mathrm{CaO}$ & $64 \cdot 52$ & 46.09 \\
\hline $\mathrm{MgO}$ & 1.92 & $2 \cdot 02$ \\
\hline $\mathrm{Na}_{2} \mathrm{O}$ & 0.27 & $1 \cdot 34$ \\
\hline $\mathrm{K}_{2} \mathrm{O}$ & 0.57 & 1.97 \\
\hline $\mathrm{SO}_{3}$ & $2 \cdot 30$ & 1.77 \\
\hline $\mathrm{Cl}$ & 0.0011 & 0.00 \\
\hline Loss on ignition & $1 \cdot 18$ & $3 \cdot 84$ \\
\hline Lime $(\mathrm{CaO})$, free & $1 \cdot 27$ & - \\
\hline $\mathrm{Na}_{2} \mathrm{O}+0.658 \mathrm{~K}_{2} \mathrm{O}$ & 0.65 & 2.64 \\
\hline $\mathrm{C}_{3} \mathrm{~A}$ & $3 \cdot 98$ & 3.98 \\
\hline 7-day (MPa) & $27 \cdot 8$ & $22 \cdot 9$ \\
\hline 28-day (MPa) & $38 \cdot 4$ & $35 \cdot 2$ \\
\hline \multicolumn{3}{|l|}{ Specific surface } \\
\hline (Blaine $\mathrm{m}^{2} / \mathrm{kg}$ ) & $340 \cdot 9$ & 398.9 \\
\hline Specific gravity & $3 \cdot 13$ & 2.94 \\
\hline Pozzolanic additive & - & $\begin{array}{c}28 \% \text { trass, } \\
6 \% \text { C-type fly ash }\end{array}$ \\
\hline
\end{tabular}

is used, all cement components attacked and assessment to their relative resistance is not possible. Also aggressive solutions with low acidic concentrations do not harm the specimens. For this reason the magnitude of low or high concentration can not be generalized. Besides, exposure period is another important factor determining the relative acid resistance of various cement based materials. In summary, care is required in interpreting the results of accelerated tests (Alegre 1978). In the interest of the reliability of the study and testing of factors of acidic attack of cement based materials and of the comparability of the results obtained, some experimental principles are recommended by Živica (2004).

In this study, the effect of different concentration of hydrochloric, nitric and sulfuric acids on the loss of weight and compressive strength of mortars incorporating pozzolanic and portland cements has been investigated.

\section{Experimental study}

\subsection{Materials}

2.1a Cement: Portland cement CEM I 32.5 and a pozzolanic cement (CEM IV-A/32.5) were used in the experimental program. Cements, in accordance with Turkish Standards (TS EN 197-1), were manufactured by Denizli Cement Plant. The cements were produced by using the same clinker. The chemical analysis and physical properties of cements are presented in table 1 . The pozzolanic cement was a blended cement incorporating $28 \%$ of trass $+6 \%$ fly ash (C type).

2.1b Aggregate: Natural river sand in accordance with TS EN 12620 was used as fine aggregates. Maximum aggregate size and specific gravity were $4 \mathrm{~mm}$ and 2.550 respectively. 
Table 2. The $\mathrm{pH}$ values of the aggressive solutions.

\begin{tabular}{lcccc}
\hline & \multicolumn{4}{c}{ Concentrations and $\mathrm{pH}$ values of inorganic acids } \\
\cline { 2 - 5 } Acid type & $0.05(\mathrm{M})$ & $0.075(\mathrm{M})$ & $0 \cdot 100(\mathrm{M})$ & $0 \cdot 125(\mathrm{M})$ \\
\hline Hydrochloric & 1.3 & 1.2 & 1 & 0.9 \\
Nitric & 1.2 & 1.1 & 0.9 & 0.8 \\
Sulfuric & 1.2 & 1.0 & 0.9 & 0.8 \\
\hline
\end{tabular}

2.1c Water: The type of mixing water that was used in the experiments was ordinary drinkable tap water with $\mathrm{pH}$ value of $6 \cdot 2 \pm 0 \cdot 1$.

2.1d Acid solutions: Solutions of hydrochloric, nitric and sulfuric acid with the concentrations of $0 \cdot 05,0 \cdot 075,0 \cdot 100,0 \cdot 125 \mathrm{~mol} / \mathrm{L}(\mathrm{M})$ were used in experiments. The $\mathrm{pH}$ values of the solutions are presented in table 2 . The $\mathrm{pH}$ values of acid solutions had been reached the neutral value $(\mathrm{pH} \cong 7 \pm 2)$ in 12 days and 14 days initial approximate $\mathrm{pH}$ values of 1 , for pozzolanic and Portland cement mortars respectively. For this reason, the solutions were renewed at every two weeks. The temperature of the solutions was $20 \pm 2{ }^{\circ} \mathrm{C}$ during a period of 120 days.

\subsection{Preparation of specimens and test procedure}

The mortar mixes have been prepared with the same river sand for two different types of cement. The cement:sand and water:cement ratios were $1: 3$ and $1: 2$ respectively for all specimens. The mixing and preparation procedures were made in accordance with TS EN 196-1. Specimens prepared with CEM I 32.5 and CEM IV-A/32.5 were labelled as M1 and M2 respectively. The fluidities of mortars have been determined by flow table test according to ASTM C124 and flow values were between 105 and $116 \%$. In order to determine the deterioration effect in early periods small test specimens were chosen. A total of 156 mortar specimens were cast into $50 \mathrm{~mm}$ cube molds including control mixes. The mortar samples were cured 24 hours at $20 \pm 2{ }^{\circ} \mathrm{C}$ and relative humidity above $80 \%$. The specimens were cured in lime-saturated water after demolding.

After 28 days of curing, the specimens were dried in an oven at $105^{\circ} \mathrm{C}$ and the initial weights were measured. Then the specimens were stored into solutions of hydrochloric, nitric and sulfuric acids with four different concentrations. For each acid and concentration, six specimens were subjected to each solution. After exposure to acids, the specimens were washed in order to remove the porous layer of the corrosion products such as soft and crystallized acidic materials or calcium salts. Then specimens were dried in an oven at $105^{\circ} \mathrm{C}$. Loss in weight of the specimens was measured weekly during the testing period of 120 days. Compressive strength of the control (non-exposed) specimens after 28 days of their hardening in water and the test specimens subjected to solutions of acids for 120 days were determined. The compressive strength values of specimens were calculated by using the original cross-sectional area of the original cubes.

\section{Results and discussions}

Average loss of weight of mortars in various acidic solutions within 120 days of testing period is presented in table 3 . The loss of compressive strength compared to control specimens after 
Table 3. Loss of weight of cement mortars after 120 days in various inorganic acid solutions.

\begin{tabular}{|c|c|c|c|c|c|c|c|c|c|}
\hline \multirow{4}{*}{$\begin{array}{l}\text { Acid } \\
\text { type }\end{array}$} & \multicolumn{9}{|c|}{ Average loss of weight of mortars (\%) } \\
\hline & \multicolumn{9}{|c|}{ Concentrations (M) } \\
\hline & \multirow{2}{*}{$\begin{array}{c}\text { Exposure } \\
\text { Time } \\
\text { (days) }\end{array}$} & \multicolumn{2}{|c|}{$0 \cdot 05$} & \multicolumn{2}{|c|}{0.075} & \multicolumn{2}{|c|}{$0 \cdot 100$} & \multicolumn{2}{|c|}{$0 \cdot 125$} \\
\hline & & M1 & M2 & M1 & M2 & M1 & M2 & M1 & M2 \\
\hline \multirow{4}{*}{$\mathrm{HNO}_{3}$} & 30 & 0.75 & $0 \cdot 70$ & 0.60 & 0.63 & 0.62 & 0.89 & 1.21 & 1.29 \\
\hline & 60 & $1 \cdot 70$ & $2 \cdot 35$ & $2 \cdot 08$ & $2 \cdot 67$ & 1.68 & $2 \cdot 42$ & 2.59 & 3.90 \\
\hline & 90 & $2 \cdot 75$ & 3.40 & $3 \cdot 25$ & 3.47 & $3 \cdot 20$ & 3.78 & 4.69 & $5 \cdot 24$ \\
\hline & 120 & $3 \cdot 40$ & $4 \cdot 15$ & 3.98 & 4.43 & $4 \cdot 72$ & 5.48 & $6 \cdot 24$ & $7 \cdot 25$ \\
\hline \multirow{4}{*}{$\mathrm{HCl}$} & 30 & 0.68 & $0 \cdot 65$ & 1.50 & $2 \cdot 23$ & 1.04 & 1.33 & 1.67 & 1.27 \\
\hline & 60 & 1.56 & 1.88 & $2 \cdot 71$ & $3 \cdot 64$ & $2 \cdot 34$ & 2.69 & 2.94 & 4.54 \\
\hline & 90 & $2 \cdot 57$ & $3 \cdot 25$ & 3.52 & 4.91 & 4.64 & $5 \cdot 20$ & 4.25 & 6.75 \\
\hline & 120 & $3 \cdot 28$ & 3.94 & 4.91 & $6 \cdot 23$ & $5 \cdot 47$ & $6 \cdot 60$ & $6 \cdot 45$ & $7 \cdot 80$ \\
\hline \multirow{4}{*}{$\mathrm{H}_{2} \mathrm{SO}_{4}$} & 30 & $0 \cdot 30$ & 0.53 & 0.32 & 0.44 & $0 \cdot 36$ & 0.40 & 0.53 & 0.66 \\
\hline & 60 & 0.89 & $1 \cdot 11$ & 0.83 & 1.22 & $1 \cdot 37$ & 1.66 & 1.12 & 1.70 \\
\hline & 90 & 1.42 & 1.89 & 1.48 & 2.07 & $2 \cdot 18$ & 3.44 & 2.52 & 2.93 \\
\hline & 120 & 2.04 & 2.98 & $3 \cdot 16$ & 3.58 & $3 \cdot 55$ & 4.83 & 4.22 & 4.94 \\
\hline
\end{tabular}

28 days of hardening in water are presented in figure 1 . The test results represent the average value of six specimens.

\subsection{The effect of acid type and concentration}

The action of $\mathrm{HCl}$ and $\mathrm{HNO}_{3}$ on cement hydration products, in particular $\mathrm{Ca}(\mathrm{OH})_{2}$ and the resulting products are presented in the following chemical equations:

$$
\begin{aligned}
& \mathrm{Ca}(\mathrm{OH})_{2}+2 \mathrm{HCl} \rightarrow \mathrm{CaCl}_{2}+2 \mathrm{H}_{2} \mathrm{O} \\
& \mathrm{Ca}(\mathrm{OH})_{2}+2 \mathrm{HNO}_{3} \rightarrow \mathrm{Ca}\left(\mathrm{NO}_{3}\right)_{2}+2 \mathrm{H}_{2} \mathrm{O}
\end{aligned}
$$

From equations (1) and (2) it can be seen that, consumption of $\mathrm{Ca}(\mathrm{OH})_{2}$ results with formation of salts of $\mathrm{CaCl}_{2}$ and $\mathrm{Ca}\left(\mathrm{NO}_{3}\right)_{2}$. By the help of water, these soluble salts may easily be transported to the outer parts of mortars. In this situation, continuous reactions increase the porosity of cement paste and increased pore volume speed up the rate of reaction.

In case of $\mathrm{H}_{2} \mathrm{SO}_{4}$ attack, the evaluation of deleterious reactions can be divided into two parts (Equations 3.a and 3.b). At the first stage, deterioration of $\mathrm{Ca}(\mathrm{OH})_{2}$ resulted with expansive gypsum formation. The gypsum then reacts with $\mathrm{C}_{3} \mathrm{~A}$ in aqeuous environment and forms a more expansive product called 'ettringite'. In this study, due to the low $\mathrm{C}_{3} \mathrm{~A}$ content of cements, mortars were less susceptible to the attack of $\mathrm{H}_{2} \mathrm{SO}_{4}$. Test results of compressive strength loss (figure 1) confirmed this theoretical assumption.

$$
\begin{aligned}
& \mathrm{Ca}(\mathrm{OH})_{2}+2 \mathrm{H}_{2} \mathrm{SO}_{4} \rightarrow \mathrm{CaSO}_{4} \cdot 2 \mathrm{H}_{2} \mathrm{O} \quad \text { (gypsum) } \\
& 3 \mathrm{CaSO}_{4}+3 \mathrm{CaO} \cdot \mathrm{Al}_{2} \mathrm{O}_{3} \cdot 6 \mathrm{H}_{2} \mathrm{O} \\
& \quad+25 \mathrm{H}_{2} \mathrm{O} \rightarrow 3 \mathrm{CaO} \cdot \mathrm{Al}_{2} \mathrm{O}_{3} \cdot 3 \mathrm{CaSO}_{4} \cdot 31 \mathrm{H}_{2} \mathrm{O} \quad \text { (ettringite) }
\end{aligned}
$$




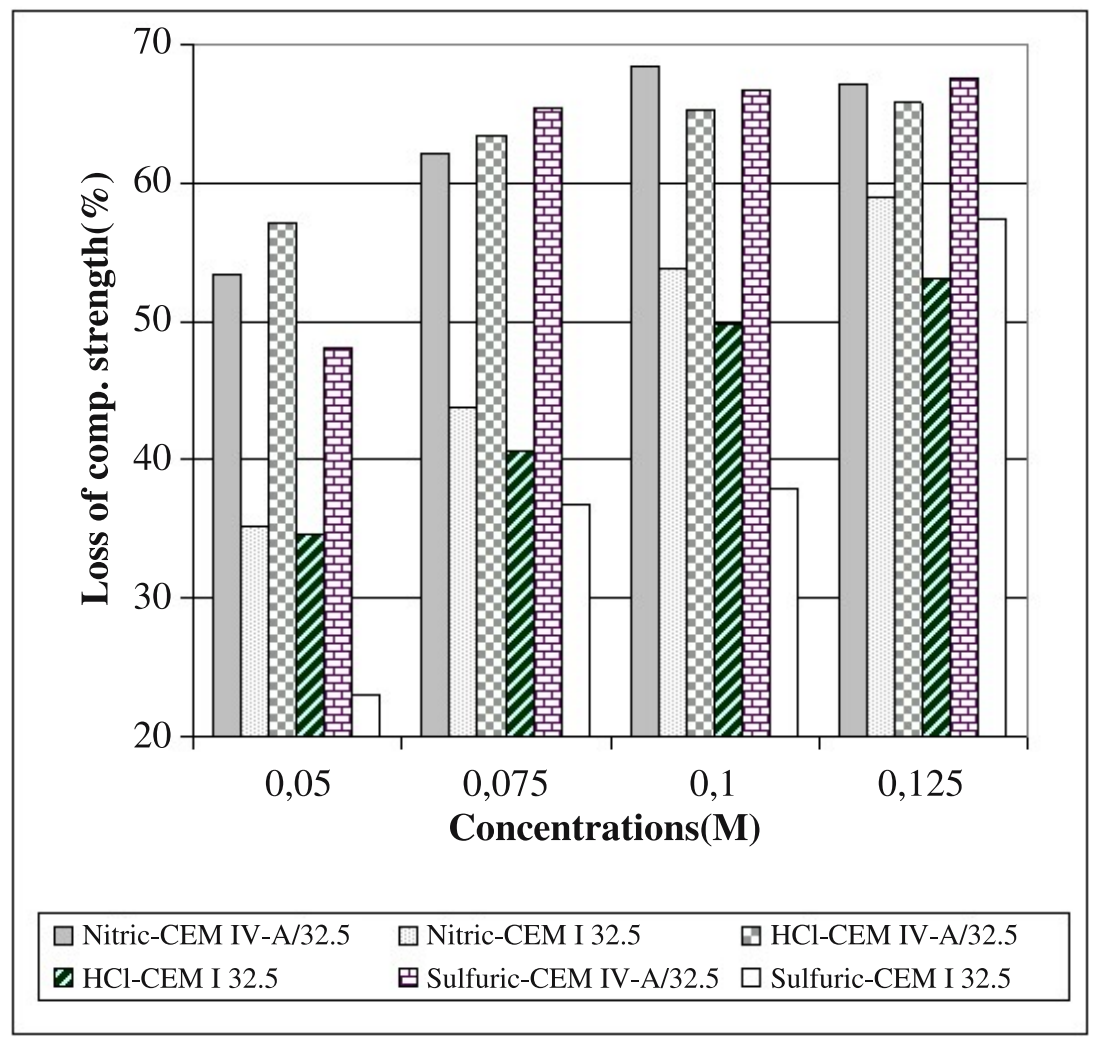

Figure 1. The loss of compressive strength of cement mortars after 120 days of attack by different inorganic acids of various concentrations compared to control specimens after 28 days of curing in water.

The rate of acid attack has been mainly related with the concentration of the solution. As can be expected, loss of weight increased with concentration of acids used (table 3). These results are in conformity with the results (Živica \& Bajza 2001) and (Pavlik 1994). The pH values of the acidic solutions were slightly reduced by increasing the acid concentration of solution (table 2). As a result, the $\mathrm{pH}$ values of diluted solutions of strong acids approximately corresponds the concentration - therefore aggressive effects of strong acids usually can be related to $\mathrm{pH}$.

Extent of deterioration of majority of samples exposed to hydrochloric and nitric acids during testing period was almost the same. The loss in weight of the samples that were exposed to sulfuric acid was the smallest because calcium sulfate (gypsum) is less soluble in water than calcium chloride or calcium nitrate. These results can be attributed to the formation of soluble calcium salts due to the reaction of acids with cements. Solubility of calcium sulfate, calcium chloride and calcium nitrate were $0.20 \%, 46.08 \%$ and $56.00 \%$ (by weight) respectively (Živica \& Bajza 2001). Due to this fact, the amount of weight loss of samples that were kept in sulfuric acid solution was the lowest. However, it should be noted that, if the W/C ratio was changed different behaviour might be observed.

The loss of strength values for all types of acids is also dependent on the concentration of the solutions (figure 1). At high concentrations this effect is more significant. For example, 
independent of the cement and acid type, the loss of strength was higher than $50 \%$, at a concentration of $0.125 \mathrm{M}$. It should be noted that, these values would be smaller if the control specimens were tested in 120 days. All acid types had similar hazardous effects on test specimens for various testing periods.

\subsection{The effect of cement type}

There are controversial results about the acid resistance of pozzolanic cements in technical literature. Živica \& Bajza (2002) claim that pozzolanic cements have better durability characteristics against acid attacks, while others (Mehta 1985; Calleja 1980; Fattuhi \& Huges 1983) claim vice versa. The results of our research have revealed that the samples prepared with pozzolanic cement have lost more weight compared to the ones prepared with Portland cement (table 3).

The main ingredient of both cements was the same Portland clinker. The above mentioned results indicate that incorporation of pozzolanic mineral additives (fly ash + trass) may not always positively affect the durability properties of cement against acid attacks.

The fineness of cement is also related with the rate of chemical reactions due to the exposed specific surfaces. During the hydration process, cement particles are converted into a mass of cement hydration products. Therefore, specific surface of the hydration products is relevant to the rate of chemical reaction. In this study, also the finer cement (pozzolanic) has lost more weight and compressive strength. The W/C ratio of mortars was kept constant. The flow values of mortars prepared with pozzolanic cements were lower than mortars made from portland cement. As a result, the compactibility of pozzolanic cement incorporated mortars for a constant compaction energy decreased. The low compactibilty of mortars resulted in a more porous surface structure. Besides, samples prepared with pozzolanic cement have larger paste volumes compared to portland cement due to lower specific gravity values (2.94-3.13 respectively). It is known that, cement pastes are more vulnerable to acid attacks than cement mortars, which incorporates fine aggregate. This result is also in conformity with the result of Pavlik and Uncik (1997).

The chemical and mineralogical properties of cement also affect the changes in $\mathrm{pH}$ values of the acidic solutions within time (Ceukelaire 1992). The equivalent alkali contents $\left(\mathrm{Na}_{2} \mathrm{O}+\right.$ $0.658 \mathrm{~K}_{2} \mathrm{O}$ ) of pozzolanic and Portland cements were $2.64 \%$ and $0.65 \%$, respectively. These values may explain the shorter neutralization period of acidic solutions for pozzolanic cements compared to Portland cements. It should be noted that, these values represent the total alkalis present in pozzolan and clinker for blended cement.

From figure 1, it can be seen that CEM I 32.5 cement (M1) is more resistant against strength loss. This behaviour is significant in all types and concentrations of acids. The higher rate of strength loss of mortars prepared with pozzolan blended cement may be attributed to the lower compactibility of mortars resulted with a more porous microstructure.

\subsection{The relationship of loss of weight and compressive strength}

The results revealed that there is a meaningful relationship between the loss of weight and loss of compressive strength for the mortar specimens produced by both cements. The coefficients of correlation has been determined as $0.76,0.82$ and 0.87 , respectively for three types of acid (hydrochloric, nitric and sulfuric) attacks during 120 days of testing periods as seen in figure 2 . 


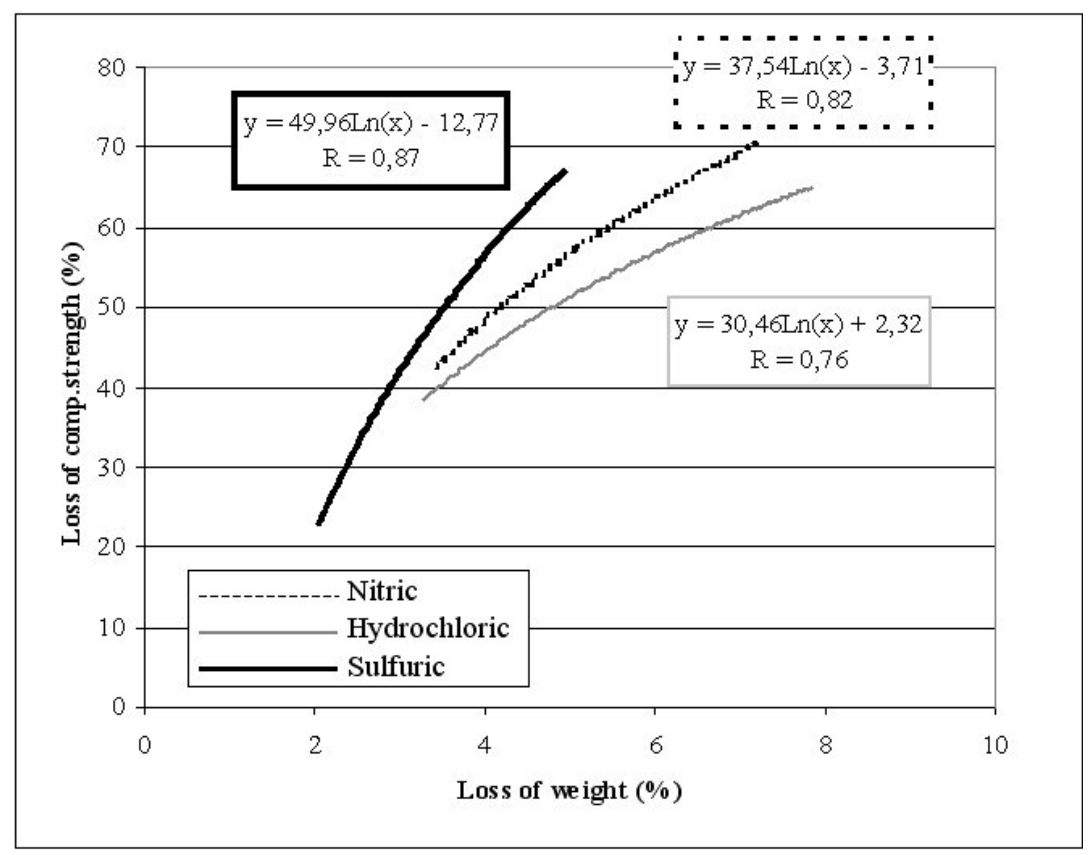

Figure 2. Loss in compressive strength of cement mortars made from both cements in relation to loss in weight after 120 days of exposure to solution.

\section{Conclusions}

Based on the experimental results reported in this paper, the following conclusions can be drawn:

(i) The loss of weight of cement mortars increases with the increasing values of acid concentration. For example, in case of $\mathrm{HNO}_{3}$, when the acid concentration increased from $0.05 \mathrm{M}$ to $0.125 \mathrm{M}$, the increase in weight loss per cent of cement mortars were $84 \%$ for ordinary Portland cement (CEM I 32.5) and $75 \%$ for pozzolanic cement (CEM IV$\mathrm{A} / 32 \cdot 5)$ at 120 days of immersion in acid solution. Similar behaviour was observed in case of other acid types.

(ii) In case of low concentrations, hydrochloric acid and nitric acid caused higher deterioration compared to sulfuric acid during the testing period. It should be noted that; sulfuric acid that produced the least soluble calcium salt had caused the least damage on test specimens especially in terms of both strength and weight loss. The better performance of mortars against sulfuric acid attack can also be attributed to the low $\mathrm{C}_{3} \mathrm{~A}$ content of employed cements.

(iii) At high concentrations $(0 \cdot 125 \mathrm{M})$, independent of the cement and acid type, the loss of strength was more than $50 \%$. Employment of solutions of excessive concentrations is not logical to compare the performance of mortars against different acid types.

(iv) The samples prepared with pozzolanic cement have lost more weight and higher compressive strength loss was observed compared to the ones prepared with ordinary Portland cement. It can be said that, incorporation of pozzolanic mineral additives (fly ash+trass) may not always positively affect the durability characteristic of cement against acid 
attack. This unexpected situation comes from consistency difference of mortars prepared with ordinary Portland cement and pozzolanic cement: By keeping the water/cement ratio constant, the consistency of mortar mixtures prepared with finer pozzolanic cement was not enough to maintain good compaction, thus more porous micro-structure was obtained compared to the ones prepared with ordinary Portland cement. It may be noted that, there is a general consensus among scientists and engineers that the performance of pozzolanic cement is better than the ordinary Portland cement against acid exposure. This study has revealed that, it is not enough to use pozzolanic cements, compactability is also important for a mortar to resist against acid attack. In this connection, attention is drawn to the fact that specifications lay emphasis on producing dense and compacted high performance cement mortar or concrete which normally includes pozzolanic materials such as fly ash for durable concrete under aggressive environments.

\section{References}

ACI Committee Report 201 2001, Guide to durable concrete, ACI Manual of concrete practice (Detroit: American Concrete Institute)

Alegre R 1978 Behaviour of cement in aggressive media (in France); Ann. JIBTB 374: 72-81

Baradan B, Yazıcı H, Ün H 2002 Durability of reinforced structures (in Turkish), University of Dokuz Eylül, dIzmir

Calleja J 1980 Durability, Proc. $7^{\text {th }}$ Int. Congress on the chemistry of cement.; 1, principal report, sub-theme VII, Paris: 2-48

Ceukelaire L D 1992 The effects of hydrochloric acid on mortar. Cem. Conc. Res. 22(5): 903-914

Ecob C R, King E S 1990 Aggressive underground environment: factors affecting durability of structure and specification of appropriate protective systems. Eds: R K Dhir, J W Green, Proc. of Int. Conf., University of Dundee, $507-517$

Fattuhi N T, Hughes B P 1983 Effect of acidic attack on concrete with different admixtures or protective coatings. Cem. Conc. Res. 13: 655-65

Gutt W H, Harrison W H 1997 Chemical resistance of concrete, Concrete 11(5): 35-37

Hewlet P C 1997 Lea's Chemistry of Cement and Concrete, Fourth edition, Elsevier, Butterworth, Heinemann, UK

Mehta P K 1985 Studies on chemical resistance of low water/cement ratio concretes. Cem. Conc. Res. 15: $969-78$

Mehta P K 1986 Concrete, properties and materials, (USA: Prentice-Hall, Inc.)

Neville A M 1997 Properties of Concrete, (London: Pittman Publishing)

Parrot L J 1991/92 Carbonation, moisture and empty pores. Adv. Cem. Res. 4: 111-18

Pavlik V 1994 Corrosion of hardened cement paste by acetic and nitric acids, Part 1: Calculation of corrosion depth. Cem. Conc. Res. 24(3): 551-562

Pavlik V, Uncik S 1997 The rate of corrosion of hardened cement pastes and mortars with additive of silica fume in acids. Cem. Conc. Res. 27: 1731-1745

Regourd M 1981 Commission RILEM 32-RCA, Resistance of concrete to chemical attack. Materials and Structures 130-137

Rostam S (Ed) 1997 Durable concrete structures design guide, Published by Thomas Telford Services Ltd.

Živica V, Bajza A 2001 Acidic attack of cement based materials - A review, Part 1. Principle of acidic attack. Constr. Build. Mater. 15: 331-340

Živica V, Bajza A 2002 Acidic attack of cement based materials - A review, Part 2. Principle of acidic attack. Constr. Build. Mater. 16: 215-222

Živica V 2004 Acidic attack of cement based materials - A review, Part 3. Research and test methods. Constr. Build. Mater. 18: 683-688 